\title{
MEANS OF INFINITE SETS I
}

\author{
ATTILA LOSONCZI
}

\begin{abstract}
We open a new field on how one can define means on infinite sets. We investigate many different ways on how such means can be constructed. One method is based on sequences of ideals, other deals with accumulation points, one uses isolated points, other deals with average using integral, other with limit of average on surroundings and one deals with evenly distributed samples. We study various properties of such means and their relations to each other.
\end{abstract}

Mathematics subject classification (2010): 26E60, 28A10, $28 \mathrm{~A} 78$.

Keywords and phrases: Generalized mean of set, Lebesgue and Hausdorff measure.

Acknowledgement. I would like to thank the anonymous referee for valuable comments and helpful criticism.

\section{REFERENCES}

[1] J. M. Borwein, P. B. Borwein, The way of all means, Amer. Math. Monthly 94 (1987), 519-522.

[2] P. S. Bullen, Handbook of means and their inequalities, vol. 260 Kluwer Academic Publisher, Dordrecht, The Netherlands (2003).

[3] Z. DARÓCZY AND Zs. PÁles, Functional Equations - Results and Advances, Springer Science \& Business Media Dordrecht (2002).

[4] Z. DARócZy and Zs. PÁLes, On functional equations involving means, Publ. Math. Debrecen 62 no. 3-4 (2003), 363-377.

[5] B. Ebanks, Looking for a few good means, Amer. Math. Monthly 119 (2012), 658-669.

[6] M. HAJJA, Some elementary aspects of means, International Journal of Mathematics and Mathematical Sciences, Means and Their Inequalities, Volume 2013, Article ID 698906, 1-9.

[7] G. H. Hardy, J. E. Littlewood, G. Pólya, Inequalities, Cambridge university press (1988).

[8] A. LosonCZI, Means of infinite sets II, prepint, arXiv:1705.06344.

[9] A. LosoncZI, Measures by means, means by measures, preprint, arXiv:1706.03658.

[10] Gy. MAKSA, Zs. PÁLES, Remarks on the comparison of weighted quasi-arithmetic means, Colloquium Mathematicum 120 (2010), 77-84. 